\title{
EVALUASI PENGGUNAAN SISTEM BARCODE DAN SCANNER DALAM PROSES DELIVERY DI COLD STORAGE PT. MULTI TERMINAL INDONESIA
}

\author{
Vivian Karim Ladesi ${ }^{1}$, Rizki Nur Ichwan ${ }^{2}$ \\ ${ }^{1}$ Prodi D III Transportasi, Fakultas Teknik - UNJ \\ ${ }^{2}$ Prodi D III Transportasi, Fakultas Teknik - UNJ
}

\begin{abstract}
Abstrak. PT. Multi Terminal Indonesia salah satu perusahaan pelayanan jasa penyimpanan barang yang tersedia gudang kering maupun gudang pendingin. Perusahaan ini sangat berupaya untuk memberikan kualitas jasanya dengan cara meningkatkan mutu pelayanan logistik di Indonesia.. Berdasarkan uraian di atas maka penulis tertarik mengambil judul "Evaluasi Penggunaan Sistem Barcode dan Scanner dalam Proses Delivery di Cold Storage PT. Multi Terminal Indonesia Unit Halal Logistic and Cold Storage." Tujuan untuk mengetahui kelebihan sistem terhadap produktivitas bongkar muat di Cold Storage, dan memberikan pemecahan masalah yang terjadi. Pengumpulan data penelitian menggunakan metode observasi dan diskusi terkait sejauh mana PT.Multi Terminal Indonesia menangani kegiatan bongkar muat menggunakan sistem dan ini sangat berdampak terhadap tingkat produktivitas perusahaan. Hal ini tentu saja dapat berdampak terhadap kemampuan bersaing dengan perusahaan lain dalam pasar global. Setelah menganalisis kelebihan penggunaan sistem tersebut, penulis mencoba memberikan solusi terbaik untuk memecahkan masalah yang ada.
\end{abstract}

Kata kunci: Evaluasi, Sistem, Produktifitas.

\section{A. PENDAHULUAN}

Pada saat ini teknologi di dunia sudah berkembang semakin pesat. Disemua bidang pekerjaan telah dikembangkan berbagai macam teknologi yang dapat mempermudah kerja manusia. Baik dalam bidang edukasi, farmasi, perdagangan, dan lainnya. Dalam bidang perdagangan sendiri berbagai macam teknologi telah diciptakan oleh manusia untuk memperlancar kegiatan perdagangan. Salah satunya adalah penggunaan teknologi barcode dalam bidang perdagangan yaitu untuk mencatat setiap barang pada setiap transaksi yang dilakukan. Barcode atau kode batang adalah sekumpulan data yang digambarkan dengan garis dan jarak spasi (ruang). Barcode menggunakan urutan garis batang vertikal dan jarak antar garis untuk mewakili angka atau simbol lainnya. Dengan demikian, setiap ketebalan garis batang dan jarak antara garis saru dengan yang lain selalu berbeda sesuai dengan isi data yang dikandung oleh kode batang atau barcode tersebut. Barcode digunakan untuk memudahkan indentifikasi berbagai hal, tentang produknya dalam berbagai transaksi. Apabila jumlah produksi massal, akan sangat sulit jika sistem barcode tidak dipergunakan dalam pengindentifikasian suatu barang. Bayangkan saja jika sebuah produk yang dibeli tidak ada barcodenya, maka untuk mengetikkan sebuah produk itu memerlukan waktu setengah menit. Dengan demikian ternyata barcode sangat banyak kegunaannya dan memang sangat penting dalam dunia modern yang memerlukan kecepatan dan keakuratan seperti saat ini mulai dari kebutuhan industri, farmasi, bidang kesehatan bahkan instansi pemerintahan seperti PLN.

\section{B. METODE PENELITIAN}

Dalam Pembahasan serta beberapa keterangan data yang diperlukan untuk mengolahnya dalam penulisan karya ilmiah penulis menggunakan data yang dilakukan dengan dengan mengamati secara langsung atas fakta yang terjadi di gudang PT. Multi Terminal Indonesia. Untuk mendapatkan data yang akurat maka data yang diambil berasal dari laporan gudang selama dua bulan. Dalam laporan tersebut terdapat data berisi jadwal waktu bongkar muat, jenis barang dan jumlah TKBM mulai aktivitas bongkar sampai selesai. Dari laporan gudang tersebut kemudian dianalisis per tanggal dan menentukan evaluasi penggunaan sistem dengan manual saat proses bongkar muat. 


\section{KERANGKA BERPIKIR}

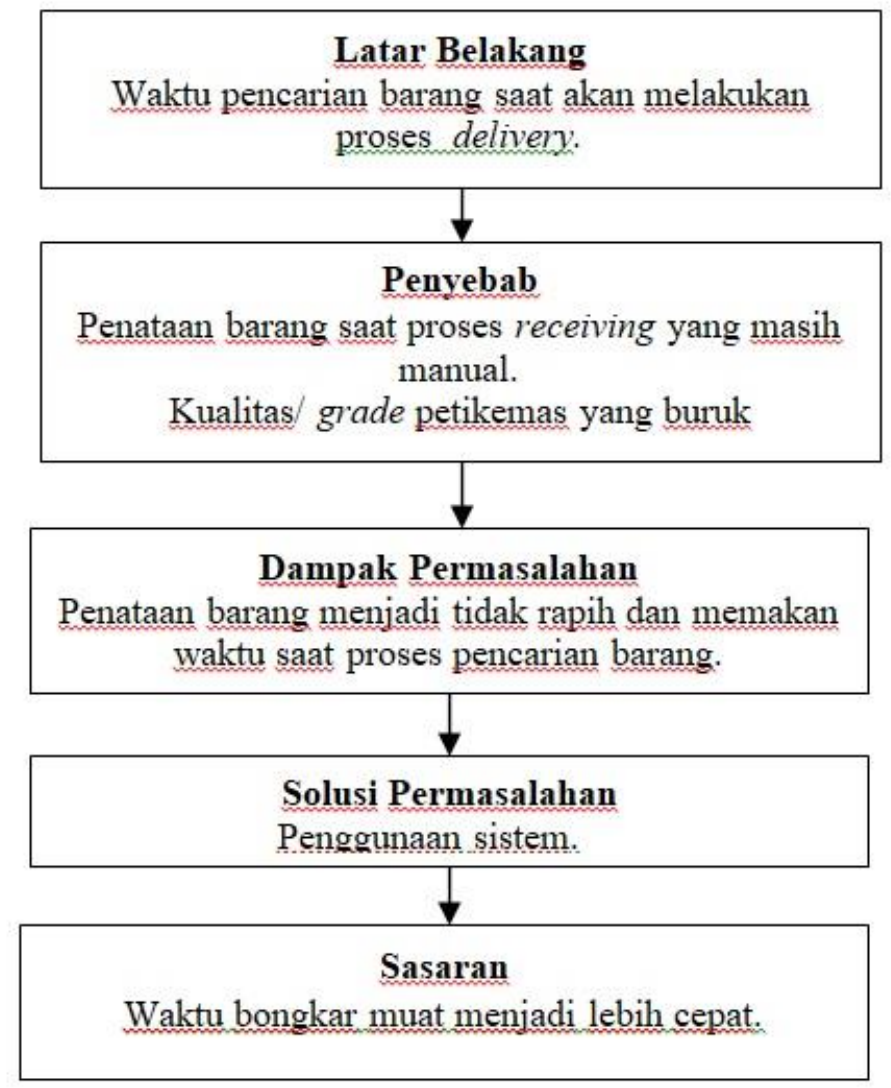

\section{PEMBAHASAN}

Dalam kegiatannya, PT. Multi Terminal Indonesia Unit Halal Logistic and Cold Storage menyiapkan keperluan yang melibatkan kedua belah pihak antara pengurus barang dan pemilik barang yang dimana barangnya disimpan di gudang PT. Multi Terminal Indonesia Unit Halal Logistic and Cold Storage. Kesiapan dokumen dan proses kegiatan delivery yang diperlukan sangatlah beragam sesuai dengan permintaan pemilik barang, syarat dari pengurus barang dan pemilik barang dalam kegiatan delivery barang domestik tersebut harus ada sebuah integrasi dari semua pihak yang terkait agar dokumen-dokumen barangnya sesuai dan tepat waktu yang telah ditentukan oleh pengurus barang dan pemilik barang. Adapun tahapan prosedur dan dokumen yang dibutuhkan dalam melakukan kegiatan delivery ini yaitu :

\section{a. Prosedur Penyerahan Barang}

1. Customer menyiapkan dokumen pendukung seperti Memo/DO asli, Invoice PBM/Mitra, Surat Jalan, yang nanti akan diserahkan kepada petugas administrasi gudang,

2. Petugas Administrasi Gudang menerima dan melakukan verifikasi dokumen seperti Memo/DO Asli, Invoice

3. Setelah dokumen lengkap, petugas administrasi gudang melakukan proses penginputan data permintaan/request barang, Proses Pembuatan Bukti Penggunaan Ruang Penumpukan (BPRP) dan Cetak kartu gate pass untuk diserahkan ke customer.

4. Petugas Billing melakukan proses Pranota dan cetak nota.

5. Petugas administrasi gudang menyetujui proses muat dan menyerahkan memo/DO yang sudah distempel ke petugas Delivery Gudang agar disiapkan barang/cargo yang sesuai permintaan yang tertera pada Memo/DO.

6. Truk Pengangkut masuk ke area parkir gudang Halal Logistic \& Cold Storage, dengan menunjukkan kartu gate pass pada petugas gate.

7. Petugas delivery menugaskan operator gudang untuk melakukan proses muat ( mencari letak barang menggunakan sistem ).

8. Dalam proses muat petugas memberikan labeling Halal Supply Chain pada barang/produk.

9. Petugas delivery memberikan stempel/cap pada memo/DO tanda barang/produk sudah sesuai dan selesai di muat. 
b. Evaluasi Penggunaan Sistem terhadap Waktu dan Jumlah Tenaga Kerja Bongkar Muat ( TKBM) dalam Proses Delivery di Cold Storage

Dalam melakukan kegiatan Delivery PT. Multi Terminal Indonesia Unit Halal Logistic and Cold Storage menyediakan perencanaan dan mengoperasikan kegiatan pendistribusian layanan jasa penyimpanan secara efektif dan efisien dengan dibantu oleh sumber daya yang sudah terlatih dalam hal pergudangan dan lapangan. Dalam sektor waktu dan jumlah TKBM saat melakukan kegiatan Delivery kurang lebih sama, hanya saja yang membedakan antara pemakaian sistem dengan yang manual, yaitu : Sistem.

\begin{tabular}{|c|c|c|c|c|c|c|}
\hline \multirow{2}{*}{ No } & \multirow{2}{*}{ Tanggal } & \multirow{2}{*}{$\begin{array}{c}\text { Jenis } \\
\text { Barang }\end{array}$} & \multicolumn{2}{|c|}{ Waktu Delivery } & \multirow{2}{*}{ Total Waktu } & \multirow{2}{*}{$\begin{array}{l}\text { Jumlah } \\
\text { TKBM }\end{array}$} \\
\hline & & & Manual & Sistem & & \\
\hline 1 & $25 / 01 / 2018$ & Apel & $08.10-09.16$ & & 66 Menit & 2 \\
\hline 2 & $26 / 01 / 2018$ & Apel & $16.19-16.34$ & & 15 Menit & 5 \\
\hline 3 & $31 / 01 / 2018$ & Apel & $08.15-09.20$ & & 65 Menit & 2 \\
\hline 4 & $31 / 01 / 2018$ & Apel & $16.15-17.00$ & & 45 Menit & 3 \\
\hline 5 & $23 / 02 / 2018$ & Apel & & $14.30-15.06$ & 36 Menit & 4 \\
\hline 6 & $27 / 02 / 2018$ & Apel & & $14.40-15.36$ & 56 Menit & 3 \\
\hline 7 & $28 / 02 / 2018$ & Apel & & $16.38-17.24$ & 46 Menit & 3 \\
\hline 8 & $28 / 02 / 2018$ & Apel & & $20.26-20.40$ & 14 Menit & 5 \\
\hline
\end{tabular}

Data Delivery Buah Apel Periode Januari - Februari 2018

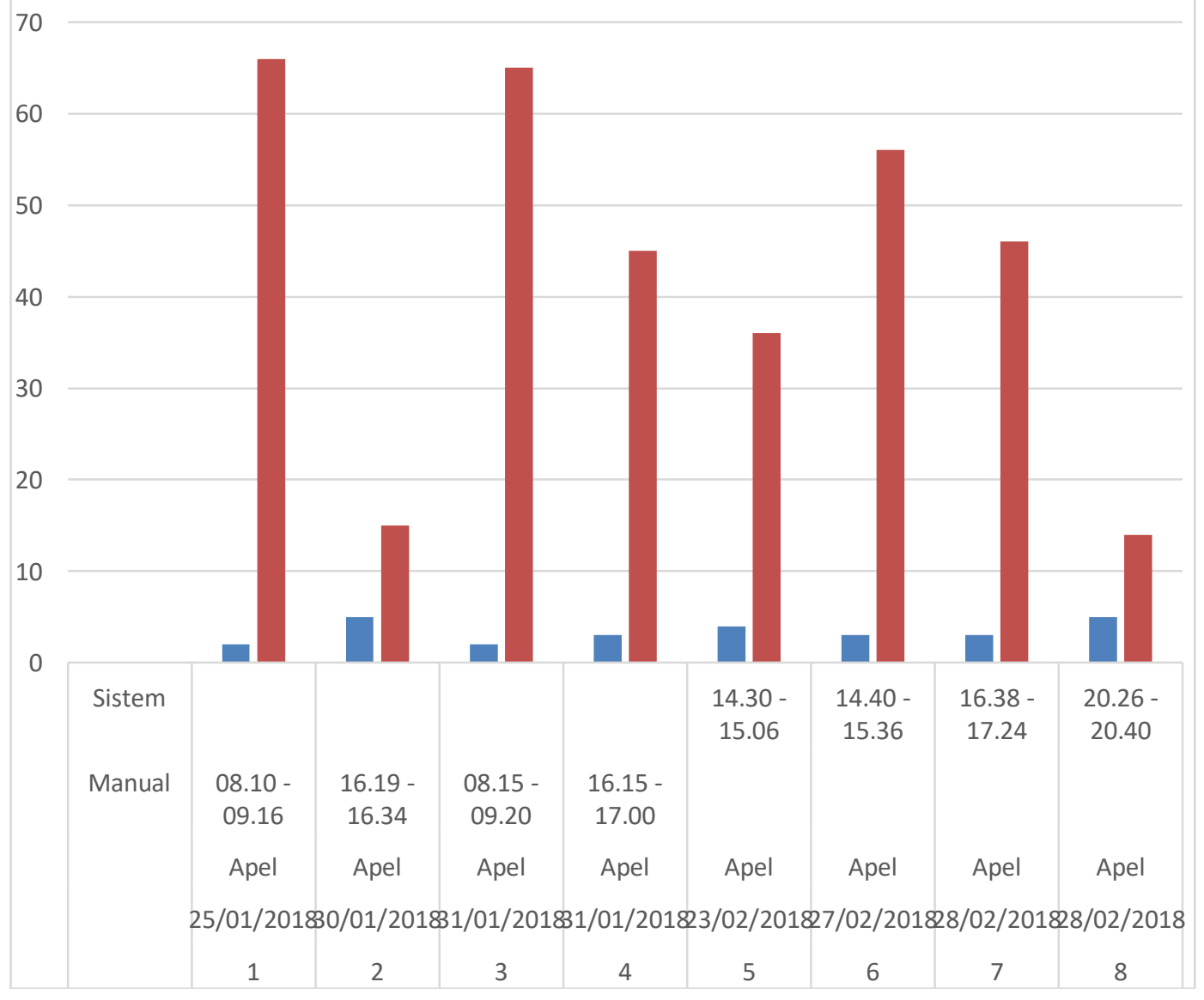

Dari data tabel diatas menunjukkan bahwa perbandingan antara pemakaian sistem dengan manual, terhadap waktu delivery selisih \pm 30 menit dan jumlah TKBM relatif tidak jauh berbeda. Dan perbedaan waktu selanjutnya yaitu saat proses pencarian barangnya, saat akan dilakukannya proses delivery. 


\section{c. Evaluasi Penggunaan Sistem terhadap Manual dalam Proses Delivery di Cold Storage}

Keuntungan Menggunakan Barcode antara lain:

1. Proses input data lebih cepat karena barcode scanner dapat membaca dan merekam data lebih cepat dibandingkan dengan melakukan proses input data secara manual.

2. Proses input data lebih tepat karena teknologi barcode mempunyai ketepatan yang tinggi dalam pencarian data.

3. Mengurangi biaya, karena dapat mengindari kerugian dari kesalahan pencatatan data, dan mengurangi pekerjaan yang dilakukan secara manual secara berulang-ulang.

4. Peningkatan kinerja manajemen, karena dengan data yang lebih cepat, tepat dan akurat maka pengambilan keputusan oleh manajemen akan jauh lebih baik dan lebih tepat, yang nantinya akan sangat berpengaruh dalam menentukan kebijakan perusahaan.

5. Kemampuan bersaing dengan perusahaan saingan / kompetitor akan lebih terjaga.

\section{E. KESIMPULAN}

1. Jika masih menggunakan manual, prosedur saat proses receiving barang lebih cepat karena tidak melewati proses scan barcode. Petugas bebas meletakkan barang di lokasi gudang atau rak yang kosong. Yang nantinya ini berpengaruh saat melakukan proses delivery barang, sebab lokasi barangnya yang belum tersistem, sehingga saat melakukan pencarian barang menjadi lama.

2. Proses input lebih akurat dan cepat dalam mencari data dan barang karena teknologi barcode mempunyai akurasi dan ketelitian yang sangat tinggi..

\section{F. SARAN}

Setelah Melakukan Praktek Kerja Lapangan selama 2 (dua) bulan di PT. Multi Terminal Indonesia, ada beberapa saran yang diberikan sebagai berikut:

1. PT. Multi Terminal Indonesia sebaiknya rutin untuk maintenance sistem di Cold Storage agar pengiriman barang secara tepat sesuai dengan kemampuan agar tidak terjadi over capacity dan keterlambatan sehingga kegiatannya terealisasi dengan sempurna.

2. PT. Multi Terminal Indonesia sebaiknya memperbaharui sistem yang sudah ada menjadi lebih bagus lagi agar data-data yang ada selalu tepat dan akurat.

\section{G. DAFTAR PUSTAKA}

IPC. Company Profile. http://www.ipclogistics.co.id/ (diakses pada tanggal 04 April 2018). 